\title{
Alginate Modified Graphene Oxide for Rapid and Effective Sorption of Some Heavy Metal Ions from Aqueous Solution
}

Ahmed Ibrahim ( $\nabla$ ahm_ch_ibr@yahoo.com )

City of Scientific Research and Technological Applications https://orcid.org/0000-0002-8593-8713

E.M. Abu Elgoud

Egyptian Atomic Energy Authority

H.F. Aly

Egyptian Atomic Energy Authority

\section{Research Article}

Keywords: Graphene oxide, Sodium alginate, removal, heavy metal, Regeneration, Selectivity.

Posted Date: January 28th, 2022

DOI: https://doi.org/10.21203/rs.3.rs-1269295/v1

License: (c) (1) This work is licensed under a Creative Commons Attribution 4.0 International License.

Read Full License 


\section{Abstract}

Herein, we investigated a facile strategy to modify the graphene oxide (GO) with sodium alginate (SA) through using tetraethylorthosilicate (TEOS) as binding agent. The GO-SA was highly loaded with carboxylated $\left(-\mathrm{COO}^{-} \mathrm{Na}^{+}\right)$groups which permitted for fast and efficient interaction with the metal ions. Therefore, the prepared composite was employed as an efficient adsorbent to uptake of some heavy metal from aqueous solution. The as-synthesized GO-SA was characterized with various advanced techniques before and after the removal process. The analysis of the experimental data showed that, the Langmuir model excellent fit the adsorption data with maximum adsorption capacities of 887.21, 161.25 and $139.62 \mathrm{mg} \mathrm{g}^{-1}$ for $\mathrm{Pb}^{2+}, \mathrm{Zn}^{2+}$ and $\mathrm{Cd}^{2+}$, respectively. Moreover, the GO-SA presented a good regeneration and reuse ability with enhancing in the removal percent for all the studied metal ions. In addition, the prepared composite showed a suitable selectivity for $\mathrm{Pb}^{2+}$ from $\mathrm{Zn}^{2+}$ and $\mathrm{Cd}^{2+}$ co-existed solution.

\section{Introduction}

Nuclear fuel cycle creates extensive amounts of aqueous waste solutions that is polluted with different heavy metals. Some of the toxic heavy metals like zinc, lead, and cadmium create serious and toxic effects to the living environment. Cadmium, zinc, and lead ions exist in both industrial and radioactive waste. Cadmium has various radioisotopes among which ${ }^{109} \mathrm{Cd}$ with a half-life of 462.9 days. It is applied in nuclear reactors as control rods and shields to absorb neutrons (Aglan et al., 2014). It also has an important role in the production of nickel-cadmium (Ni-Cd) rechargeable batteries and as corrosionprotection coating for iron and steel. General industrial utilizes for cadmium are in alloys, batteries, solar cells, pigments, coatings (electroplating), and plastic stabilizers (Carolin et al., 2017). Zinc present in waste water streams of many industries such as steel works, in electroplating process and in intermediate level active waste (Ali \& Ache, 1985). The addition of zinc to nuclear reactors greatly reduces corrosion processes, including stress corrosion cracking. Lead is highly toxic and can harm the nervous system and kidneys. The several sources of lead include effluents from battery manufacturing, painting pigment, steel industries, fuels, coating industries, and explosive manufacturing. Since lead effectively absorbs electromagnetic radiation of short wavelengths, it is utilized as a protective shielding around nuclear reactors for gamma rays, particle accelerators and X-ray equipment. It is also used as containers for transporting and storing radioactive materials (Dodd, 2004). Numerous trials were carried out to remove various heavy ions from the aqueous solution using adsorption approach. Rodríguez et al., 2020, studied the removal of aluminum and copper from acid mine drainage wastewater. They found that the decoration of $\mathrm{GO}$ with zinc oxide nanoparticles $(\mathrm{ZnO})$ can remove the aluminum (Al) and copper $(\mathrm{Cu})$ from acidic waters $(\mathrm{pH}=4)$ with adsorption capacity $19.9 \mathrm{mg} / \mathrm{g}$ for Al and $33.5 \mathrm{mg} / \mathrm{g}$ for Cu over $30 \mathrm{~min}$. Katubi et al., 2021, successed in adsorption of $636.94 \mathrm{mg} \mathrm{g}^{-1}$ of $\mathrm{Pb}$-ion onto $\mathrm{MnFe}_{2} \mathrm{O}_{4} / \mathrm{GO}$ composite at $\mathrm{pH}=7$ and the optimum contact time was $30 \mathrm{~min}$. Li et al., 2020, investigated the preparation of graphene oxide/chitosan complex and its behavior for adsorption of copper, lead, and cadmium ions from simulated wastewater. They showed that the one gram of GO/CS composite can adsorb $60.7 \mathrm{mg}$ of 
copper, $48.7 \mathrm{mg}$ of lead, and 32.3mg of cadmium at time $90 \mathrm{~min}$ and $(\mathrm{pH}=6)$. Pourbeyram, 2016, studied the modified the graphene oxide surface with zirconium and phosphate to synthesis graphene oxidezirconium phosphate (GO-Zr-P) nanocomposite. He observed that, the prepared composite (GO-Zr-P) can achieve maximum adsorption capacity for $\mathrm{Pb}$ (II) (363.42 $\left.\mathrm{mg} \mathrm{g}^{-1}\right), \mathrm{Cd}(\mathrm{II})\left(232.36 \mathrm{mg} \mathrm{g}^{-1}\right), \mathrm{Cu}(\mathrm{II})$ $\left(328.56 \mathrm{mg} \mathrm{g}^{-1}\right)$, and $\mathrm{Zn}(\mathrm{II})\left(251.58 \mathrm{mg} \mathrm{g}^{-1}\right)$ at $\mathrm{pH}=6$ and after 20 min contact time. Removal of lead from aqueous solution by using nanocomposite of zinc oxide/graphene oxide ( $\mathrm{ZnO} / \mathrm{GO})$ have been investigated by Ahmad et al., 2020. They reported that at $\mathrm{pH}=5$ after $160 \mathrm{~min}$ mixing time the $\mathrm{ZnO} / \mathrm{GO}$ possess maximum adsorption capacity of $418.78 \mathrm{mg} / \mathrm{g}$ for $\mathrm{Pb}$ (II). Bagheri et al., 2020, evaluated the prepared $\mathrm{rGO}-\mathrm{Fe}^{0} / \mathrm{Fe}_{3} \mathrm{O}_{4}$-PEI nanocomposite for lead and cadmium removal. Their work showed that the maximum adsorption capacity $60.24 \mathrm{mg} \mathrm{g}^{-1}$ for lead and $54.47 \mathrm{mg} \mathrm{g}^{-1}$ for cadmium at $\mathrm{pH}=6$, and 60 min of contact time. Kong et al., 2020, studied the adsorption of $\mathrm{Pb}^{2+}$ and $\mathrm{Cu}^{2+}$ on graphene oxideterminated hyperbranched amino polymer-carboxymethyl cellulose ternary nanocomposite (GO-HBP-NH ${ }_{2}^{-}$ $\mathrm{CMC}$ ). They reported that the maximum adsorption capacity of $\mathrm{GO}-\mathrm{HBP}-\mathrm{NH}_{2}-\mathrm{CMC}$ towards $\mathrm{Pb}^{2+}$ is 152.86 $\mathrm{mg} \mathrm{g}^{-1}$ and $\mathrm{Cu}^{2+} 137.48 \mathrm{mg} / \mathrm{g}$ at $\mathrm{pH}=5$ and mixing time $240 \mathrm{~min}$. Removal of $\mathrm{Pb}(\mathrm{II})$ has been studied by partially reduced graphene oxide- $\mathrm{Fe}_{3} \mathrm{O}_{4}$ composite from aqueous solutions by Guo et al., 2018. They found that one gram of the nano adsorbent can interact with $373.14 \mathrm{mg}$ of $\mathrm{Pb}^{2+}$ at $\mathrm{pH}=6$ within $10 \mathrm{~min}$. Yang et al., 2020, employed the oily sludge pyrolysis residue for decontaminated the heavy metal from synthetic flotation wastewater. The experimental results showed that the maximum uptake of the used adsorbent for $\mathrm{Cd}^{2+}\left(106.16 \mathrm{mg} \mathrm{g}^{-1}\right), \mathrm{Pb}^{2+}\left(140.65 \mathrm{mg} \mathrm{g}^{-1}\right)$ and $\mathrm{Cu}^{2+}\left(128.04 \mathrm{mg} \mathrm{g}^{-1}\right)$ at $\mathrm{pH}<7.5$ and contact time $45 \mathrm{~min}$. Ge and $\mathrm{Ma}, 2015$, used the microwave irradiation to fabricate triethylenetetraminemodified graphene oxide/CS (TGOCS). The affinity of TGOCS towards $\mathrm{Cr}(\mathrm{IV})$ from aqueous solution was $219.5 \mathrm{mg} \mathrm{g}^{-1}$.

Sodium alginate $(S A)$ is an anionic linear polysaccharide based on alternating blocks of $\beta-(1 \rightarrow 4)$-linked $d$ mannuronic acid $(M)$ and $\mathrm{a}-(1 \rightarrow 4)$-linked I-guluronic $(\mathrm{G})$ residues. With a high density of free hydroxyl and carboxyl groups located over the alginate backbone, these are making the (SA) highly reactive and amenable for chemical modifications and complexation. On the other hand, the GO found as nanosheets with one $\mathrm{C}$-atom thickness and various $\mathrm{O}$-function groups distributed over $\mathrm{GO}$ nanosheet surface. Several studies were investigated in order to combine the GO and sodium alginate; Yu et al., 2019, were prepared hydrogel beads composed of polyvinyl alcohol (PVA)/graphene oxide (GO)-sodium alginate (SA) via crosslinking in saturated solution of solution of saturated boric acid and $\mathrm{CaCl}_{2}$. They observed that PVA and SA molecules were bonded with $\mathrm{GO}$ layers via $\mathrm{H}$-bond which cause significate disorder of the layered structure of GO. In addition, the increasing in the GO dose the hydrogel beads lose its ballbility and network structure, leading to enhance its permeability and adsorption capacity towards $\mathrm{Pb}^{2+}(279.43 \mathrm{mg}$ $\mathrm{g}^{-1}$ ). Yu et al., 2021, were employed the vacuum filtration technique to fabricate self-support composite membrane formed from GO/ SA/1, 2-Propanediamine (PDA) for adsorption of $\mathrm{Pb}^{2+}$. The adsorption experiments revealed that the equilibrium adsorption was reached after $20 \mathrm{~min}$. And according to Langmiur, the maximum adsorption capacity for $\mathrm{Pb}^{2+}$ was $189.25 \mathrm{mg} \mathrm{g}^{-1}$. He et al., 2020, investigated a novel hydrogel adsorbent consisted of yttrium-immobilized-graphene oxide-alginate (Y-GO-SA) for 
removal of adsorption of As and tetracycline (TC). The adsorption process was $\mathrm{pH}$-dependent. The maximum adsorption capacities were obtained $273.39 \mathrm{mg} \mathrm{g}^{-1}\left(\mathrm{As}(\mathrm{V})\right.$ ), and $477.9 \mathrm{mg} \mathrm{g}^{-1}$ (TC). Jiao et al., 2016, were prepared porous aerogel constructure from sodium alginate/graphene oxide (SAGO) using insitu crosslinking and freeze-drying strategy. The addition of GO, as reinforcing filler, enhance various properties of the obtained SAGO aerogel such as; porous structure, mechanical strength, elasticity, and the compression strength. Referring to Langmuir isotherm, the maximum removing capacities for $\mathrm{Cu}^{2+}$ $\left(98.0 \mathrm{mg} \mathrm{g}^{-1}\right)$ and $\mathrm{Pb}^{2+}\left(267.4 \mathrm{mg} \mathrm{g}^{-1}\right)$. Zhou et al., 2018, were employed the hydrothermal polymerization of lignin, sodium alginate and $\mathrm{GO}$ in an aqueous solution to form 3D porous composite (PG/L/SA). The results obtained from the adsorption experiments showed that the PG/L/SA achieved maximum adsorption ability of $\mathrm{Cd}(\mathrm{II})$ and $\mathrm{Pb}$ (II) of 79.88 and $226.24 \mathrm{mg} / \mathrm{g}$, respectively. Pan et al., 2018, were used sacrificial template of polystyrene particles to form porous calcium alginate/graphene oxide composite aerogel (mp-CA/GO). They observed that, the as ( $\mathrm{mp}-\mathrm{CA} / \mathrm{GO})$ possess suitable adsorption capacities towards $\mathrm{Pb}^{2+}\left(368.2 \mathrm{mg} \mathrm{g}^{-1}\right), \mathrm{Cu}^{2+}\left(98.1 \mathrm{mg} \mathrm{g}^{-1}\right)$ and $\mathrm{Cd}^{2+}\left(183.6 \mathrm{mg} \mathrm{g}^{-1}\right)$ and adsorption equilibrium achieved after $40 \mathrm{~min}$. Yang et al.,2014, was employed a facile preparation method for synthesis CS/GO via H-bonding interaction between CS and GO. They found that the CS/GO possessed adsorption capacity $202.5 \mathrm{mg} / \mathrm{g}$ to $\mathrm{Cu}(\mathrm{II})$.

As we can see before, the scientists used various strategies for preparation of GO/SA hydrogel (porous structure, beads, layer, aerogel, etc). The preparation of these composites was required multi-steps. Moreover, a part of the bind sites was consumed by crosslinking or by shieling interior in the bulk gel. As a result, the time for reaching equilibrium will be elongated and the adsorption capacity will be reduced.

In this work, we suggest simple modification of the GO surface with SA through using TEOS as bridge to link the hydroxyl groups of both GO and SA. This manner will provide extra and efficient binding site ($\mathrm{COO}^{-} \mathrm{Na}^{+}$) available for highly rapid chelating the heavy metal ion. The GO-SA composite was fabricated using mild and green conditions, characterized with different techniques and applied for removal of $\mathrm{Pb}^{2+}$, $\mathrm{Zn}^{2+}$ and $\mathrm{Cd}^{2+}$ from aqueous solution using batch technique.

\section{Experimental}

\subsection{Materials and instrumentation}

The chemicals required were of analytical grade and utilized without further purification. $\mathrm{H}_{2} \mathrm{SO}_{4}(95-97 \%$, Riedel deHaen), $\mathrm{H}_{2} \mathrm{O}_{2}$ (36\%, Pharaohs Trading and Import), $\mathrm{HCl}$ (30\%, El Salam for Chemical Industries), $\mathrm{KMnO}_{4}(99 \%$, Long live), and graphite (200mesh, 99.99\%, Alpha Aesar), sodium alginate (Alpha Chemika, analytical reagent), TEOS (99\%, Across), ethanol absolute (Sigma-Aldrich), $\mathrm{Pb}\left(\mathrm{NO}_{3}\right)_{2}$ (99\%, SigmaAldrich), $\mathrm{Cd}\left(\mathrm{NO}_{3}\right)_{2} \cdot 4 \mathrm{H}_{2} \mathrm{O}$ (99\%, Sigma-Aldrich), $\mathrm{ZnSO} 4.5 \mathrm{H}_{2} \mathrm{O}$ (99\%, Loba Chemie).

Analytical balance (CP 2245, Sartorius, USA.), Hot plate stirrer (IKA, C-MAG HS7, IKA®-Werke GmbH \& Co. KG, Germany), pH meter (3510, Genway), Hot plate stirrer (SB 162, Stuart, UK.), Centrifuge, (Mikro 220R, 
Hettich, UK.).

\subsection{Preparation of GO and GO-SA composite}

GO was synthesized according to our previous strategy (Abd-Elhamid et al., 2018). The GO-SA was fabricated via simple mixing approach. In detail, $(4.0 \mathrm{~g})$ of sodium alginate was added to $1000 \mathrm{~mL}$ distill water under stirring until solution become clear. Thereafter, GO $(0.15 \mathrm{~g})$ were appended to the alginate solution at constant stirring to form homogeneous GO-alginate suspension solution (a). On another beaker, alcoholic solution of TEOS was prepared separately, by adding $5.0 \mathrm{ml}$ TEOS to $25 \mathrm{ml}$ absolute ethanol solution (b). Afterwards, solution (b) drop-wisely added to the solution (a), The final solution was kept stirring for $48 \mathrm{hr}$ at $60^{\circ} \mathrm{C}$. The resulted viscous solid was separated by filtration washed several times with distilled water and stored for further use.

\subsection{Batch Adsorption of heavy metals}

A stock solution of $1000 \mathrm{mg} / \mathrm{L}$ was prepared by dissolving proper amount of every metal ion in double distilled water. A batch sorption experiments were conducted in order to study the parameters that affect the sorption of $\mathrm{Pb}(\mathrm{II}), \mathrm{Cd}(\mathrm{II})$ and $\mathrm{Zn}(\mathrm{II})$ such as shaking time, $\mathrm{pH}, \mathrm{v} / \mathrm{m}$, initial metal concentration and temperature, where the optimized conditions were determined. The metal concentration was

spectrophotometrically determined with a Shimadzu double beam spectrophotometer by using 4-(pyridyl2-azo) resorcinol (PAR) (Marczenko, 1976). Batch experiments were done by shaking $2.8 \mathrm{mg}$ of the prepared graphene oxide alginate with $5.0 \mathrm{ml}$ of the solution of metal ions in a thermo-stated shaker bath adjusted at $25^{\circ} \mathrm{C}$ to achieve an adsorption equilibrium condition. The percentage removal, $\mathrm{R} \%$, of the $\mathrm{Pb}(\mathrm{II}), \mathrm{Cd}(\mathrm{II})$ and $\mathrm{Zn}(\mathrm{II})$ at equilibrium was calculated as given in Eq. 1.

$$
R \%=\left(\frac{C_{o}-C_{e}}{C_{o}}\right) * 100
$$

1

Where $C_{o}$ and $C_{e}$ are the initial and equilibrium concentrations $(\mathrm{mg} / \mathrm{L})$ of metals ions in solution, respectively.

\subsection{Characterization}

The prepared material was characterized by Transition Electron Microscope (TEM) analysis was carried out by a JEM-1010 unit (JEOL Ltd., Tokyo, Japan). Scanning Electron Microscope (SEM) (JEOL GSM6610LV. Japan) with additional EDS unit, Light Optical Microscopy (LOM) (BX61, Olympus, Japan), Thermo-Gravimetric Analysis (TGA, Shimadzu Thermal Gravimetric Analysis (TGA) - 50, Japan). Elemental composition of $\mathrm{Cu}$ (II) and Co (II) sorption on GO-C was displayed by an Oxford energydispersive X-ray (EDX) spectrometer (Oxford Link ISIS, Japan). Fourier Transmission Infra-Red Spectroscopy (FT-IR) (8400s, Shimadzu, Japan) covered the range from 400 to $4000 \mathrm{~cm}^{-1}$ and Raman Spectroscopy (Bruker, Senterra II, Germany). 
2.5. Adsorption Kinetics Study (see supplementary materials)

2.6. Adsorption isotherm (see supplementary materials)

2.7. Thermodynamic Study of Adsorption (see supplementary materials)

3. Results And Discussion

\subsection{Characterization}

\subsubsection{TEM and SEM}

The TEM images of the GO layer appear as a single highly transparent sheet (Abd-Elhamid et al., 2018). After modification of the GO surface with alginate, the GO-SA composite layer appears to be dusk and cloudy, see Fig. 1a-c, which may be due to the modification with alginate.

The morphological structure of GO-SA composite was determined with SEM technique. Fig. 1d-h, presented the SEM photographs of the GO-SA at various magnifications. At low magnifications the composite appears as fully separated distributed particles (Fig. 1d) with increase in the magnification power the layered structure become clearer and cracks appears at the composite surface, Fig. 1e \& f. At higher magnification, the cracks could be detected clearly into separated bulky structure which may be refers to the dried sodium alginate that coated the GO surface Fig. $1 \mathrm{~g} \& \mathrm{~h}$. However, the morphology of the composite was different after the adsorption of the metal ions, see Fig. S1. Moreover, the resulted composite-metal (GO-SA-M) morphological structure depend on the type of the adsorbed metal ions. Where, after adsorption of $\mathrm{Pb}$-ions the GO-SA-Pb complex seems as layers with particles deposited on its surface. While in case of adsorption of Cd-ions the structure of GO-SA-Cd complex not greatly alter than the original composite. Moreover, at adsorbing of Zn-ions the yielded GO-SA-Zn complex looks alike great agglomerated bulky structure. The alteration of the morphological structure of the composite after the adsorption process may indicate that the adsorption of the selected metal ions is by crosslinking adsorption mechanism.

\subsubsection{FIIR}

The chemical structure of the GO and modified GO (GO-SA) were illustrated employing the FTIR spectra, Fig. 2a. The GO possess bands at $3433 \mathrm{~cm}^{-1}, 1635 \mathrm{~cm}^{-1}, 1398 \mathrm{~cm}^{-1}$ and $1033 \mathrm{~cm}^{-1}$ referring to $\mathrm{O}-\mathrm{H}$ stretching, $\mathrm{O}-\mathrm{H}$ bending, $\mathrm{COOH}$ and $\mathrm{C}-\mathrm{O}$ stretching, respectively (Febrianastuti et al., 2019). After modification of GO by the alginate and TEOS as crosslinker, the GO-SA shows bands at $3434 \mathrm{~cm}^{-1}$ (adsorbed water and O-H stretching), $2923 \mathrm{~cm}^{-1}\left(\mathrm{CH}_{2}\right.$ group), bands at 1740 and $1347 \mathrm{~cm}^{-1}$ belongs to vibration modes of $\mathrm{C}-\mathrm{O}$ bond related to the $\mathrm{COOH}$ groups. The peaks at 1625 and $1413 \mathrm{~cm}^{-1}$ crossponding to the asymmetric and symmetric stretching modes of carboxylate salt groups (-COONa), respectively (Nigiz, 2020). 
The peaks in rang $1100-1000 \mathrm{~cm}^{-1}$ assigned to the (C-O, Si-O and C-O-C stretching) of the GO, TEOS and glycoside bonds in the polysaccharide, respectively (Fig. 2a). After adsorption of metal ions, FTIR spectra of GO-SA-M complexes was differ from the GO-SA spectrum. Where, the intensity of the bands in the region 1740-1100 highly weaken (Allouss et al., 2020). These observations may be due to the complexation interaction between the various function groups of the GO-SA composite and the M-ions (Cui et al., 2015), see Fig. S3.

\subsubsection{TGA}

Thermogravimetric analysis of the GO and GO-SA composite was investigated to detect the influence of the modification step on the thermal properties of the prepared composite. The TGA graph of the GO and GO-SA composite were presented in Fig. 2b. As obtained, four degradation steps were required for GO decomposition namely, Fig. 2b, (i) liberation the surface moisture evaporation (19.6\%) in the range of 28$88^{\circ} \mathrm{C}$, (ii) releasing of adsorbed water $\left(4.07 \%\right.$ ), in the range of $88-158^{\circ} \mathrm{C}$, (iii) decomposition of oxygenated function groups $-\mathrm{OH}$ and $\mathrm{C}-\mathrm{O}-\mathrm{C}(20.50 \%)$ in the range of $158-215^{\circ} \mathrm{C}$, and (iv) pyrolysis of $\mathrm{COOH}$ in the range of $215-320^{\circ} \mathrm{C}$.

On the other hand, the thermograph for GO-SA showed seven pyrolysis stages, as illustrated in Fig. 2b. The existence the alginate decorated the GO-surface, will minimize the quantity of the adsorbed moisture and bounded surface water. This is due to the hydroxyl $(-\mathrm{OH})$ on the $\mathrm{GO}$ surface. This is accounted on the possible bounding moisture and water molecule via $\mathrm{H}$-bonding involved in the functionalization process. Upon linking of the $\mathrm{GO}$ with alginate via silane bonding, the thermal characters of the synthesized composite (GO-SA) extremely differ from that related to the GO. Where, the GO-SA release $8.00 \%$ moisture at temperature $\left(78^{\circ} \mathrm{C}\right)$ which is lower than that for the $\mathrm{GO}$, see Fig. $2 \mathrm{~b}$. This may be due to partial ionic bond formation between the Na-ion of the alginate and the water molecule. Which resulted in attract low amounts of moisture molecules. On the other hand, the amount of intermolecular water by the GO-SA (7.22\%) which evaporated at $\mathrm{T}=181^{\circ} \mathrm{C}$, is larger than that showed for GO, refer Fig. $2 \mathrm{~b}$. This may be attributed to the properties of the alginate hydrogel to retain extra water molecules within its chain, which require higher temperature for release it (Ablouh et al., 2019; Gopalakannan et al., 2016).

Moreover, Liu et al., 2015, demonstrated that sodium alginate started to decomposes from 202 to $289^{\circ} \mathrm{C}$, this might be referred with the break of glycosidic bonds, dehydration, decarboxylation and decarbonylation of the alginate. Herein, GO-SA composite smoothy degrade and its weight reduced by $25.20 \%$ at $181-268{ }^{\circ} \mathrm{C}, 14.20 \%$ at $268-335^{\circ} \mathrm{C}, 11.24 \%$ at $335-472{ }^{\circ} \mathrm{C}$ and $28.00 \%$ at $472-603{ }^{\circ} \mathrm{C}$. This behavior may be ascribed as, the alginate chains modified the $\mathrm{GO}$ freely extend in the space and these chains gradually pyrolysis. Moreover, the alginate chains may be crosslinked with silane linker which leads to enhance the thermal properties of the prepared composite.

\subsubsection{EDS analysis}

The EDS is an important device that required to detect the elements related the prepared sample. In this research the composite (GO-SA) prepared employing GO, SA and TEOS, therefore, the EDS analysis detect 
the presence of $\mathrm{C}, \mathrm{O}, \mathrm{Si}$ and $\mathrm{Na}$ atoms in the analyzed sample. By blending the composite materials with the M-ion ( $\mathrm{Pb}, \mathrm{Cd}$ and $\mathrm{Zn}$ ) solutions. The EDS analysis detect the appearance of $\mathrm{Pb}, \mathrm{Cd}$ and $\mathrm{Zn}$ and absence of $\mathrm{Na}$ in the analysis data of the analyzed samples. These results confirm that the adsorption process proceeded through cation exchange mechanism, Fig. 3.

\subsection{Adsorption Experiments 3.2.1 Effect of contact time}

In figure 4 a the relation between removal percent $(\% \mathrm{R})$ against contact time is illustrated. From this figure it's clear that the removal percent $(\% \mathrm{R})$ is quite fast and reach equilibrium within 1.0 min shaking. The highly rapid sorption kinetics of the studied heavy metal ions may be referee to either surface complexation or strong chemisorption of these heavy metals on the GO-SA surface (Liu et al., 2015) and the separated layer structure of the GO-SA as appeared in the TEM analysis, see Fig. 1a-c.

To assess these results kinetically, the second order kinetic equation was applied (see supplementary materials). The results obtained are given in Fig. $4 \mathrm{~b}$. The relation coefficient and other various parameters were calculated from the linear relation between $t$ and $t / q_{e}$ and summarized in Table S2. We noted that, the $R^{2} \geq 0.995$ (close to unit), moreover, the calculated $\left(q_{c a l}, \mathrm{mg} \mathrm{g}^{-1}\right)$ for all tested metal ion were greatly close to the adsorption capacity values measured from experiments $\left(\mathrm{q}_{\mathrm{exp}}, \mathrm{mg} \mathrm{g}^{-1}\right)$. Therefore, we suggested that, the adsorption kinetics follow the pseudo-second-order kinetics model and the adsorption rate was mainly described via the chemical adsorption process.

\subsubsection{Effect of solution $\mathrm{pH}$}

In sorption process the $\mathrm{pH}$ values of the aqueous solution consider an important factor. Where, the variation in the solution $\mathrm{pH}$ will induce on the behavior of adsorbent surface-active groups and the nature of the adsorbate species. Here, we adjusted the $\mathrm{pH}$ values according to the nature of heavy metal to avoid precipitation. It was found that, the removal efficiency of the GO-SA is highly dependence on the $\mathrm{pH}$ value of the contaminated solution, see Fig. 4c. At low pH values of the removal efficiency (\%R) relatively low and sharply increase with further increase in the solution $\mathrm{pH}$. This behavior may be attributed to, the GOSA composite possess carboxylated $\left(\mathrm{COO}^{-} \mathrm{Na}^{+}\right)$groups on its surface and these groups were the responsible on interaction with the contaminated species. Therefore, at low $\mathrm{pH}$ the concentration of $\mathrm{H}^{+}$is high and will block the adsorption active site against the heavy metal. On the other hand, by increasing the $\mathrm{pH}$ value the number of the $\mathrm{H}^{+}$ion will be minimized and the surface-active groups ( $\mathrm{COO}^{-}$) become highly ionized which provide a favorable sorption site for the heavy metal ion (Wang et al., 2016; Huang et al., 2018).

\subsubsection{Effect of initial metal ion concentration}

The metal ion concentration displays a vital role on retarding the mass transfer resistance among the aqueous and solid phases (Nurhajawarsi et al., 2018). The influence of the initial metal ion concentration was studied using batch approach in rang (200-1000 $\left.\mathrm{mg} \mathrm{L}^{-1}\right)$ for removal percent (\%R) of $\mathrm{Pb}^{2+}$ and (25- 
$150 \mathrm{mg} \mathrm{L}^{-1}$ ) for $\mathrm{Cd}^{2+}$ and $\mathrm{Zn}^{2+}$, Fig. $4 \mathrm{~d}$. It is clearly obvious that, the GO-SA uptake percent decrease with further increase in the initial concentration of the metal ion. This manner referee to at low initial concentration of the metal ions, the number of metal ions is relatively low compared with the number of available active surface function groups. While, at high initial concentration of metal ions, the ratio of the number of metal ions available binding sites at the composite surface is higher. Therefore, the adsorption percent (\%R) tend to decrease (Taamneh et al., 2017).

Numerous isotherm models have been employed. Among these Langmuir and Freundlich models are the most applied (see supplementary materials) to fit the experimental results in order to describe the interaction behavior between the metal ions and the used composite GO-SA (Fig. 4e \& f). The calculated parameters and correlation coefficient, $R^{2}$, revealed to the used models were recorded in Table 1 . The $R^{2}$ values related to Langmuir model was $>0.98$ which is higher than that of Freundlich isotherm for all studied metal ions. This clarify that Langmuir model is more suitable to represent the experimental data. Moreover, according to Langmuir model the GO-SA composite presents the maximum adsorption capacities ( $\left.\mathrm{mg} \mathrm{g}^{-1}\right) ; \mathrm{Pb}$ (884.96), Cd (134.23) and Zn (155.04), see Table 1.

Table 1

Langmuir and Freundlich constants for adsorption of $\mathrm{Pb}^{2+}(\mathrm{t}=1 \mathrm{~min}$, Dose $=2.8 \mathrm{mg}, \mathrm{V}=5 \mathrm{ml}, \mathrm{pH}$ $\left.=4, \mathrm{~T}=25^{\circ} \mathrm{C}\right) \mathrm{Cd}^{2+}\left(\mathrm{t}=1 \mathrm{~min}\right.$, Dose $\left.=2.8 \mathrm{mg}, \mathrm{V}=5 \mathrm{ml}, \mathrm{pH}=7, \mathrm{~T}=25^{\circ} \mathrm{C}\right)$ and $\mathrm{Zn}^{2+}(\mathrm{t}=1 \mathrm{~min}$, Dose $=2.8 \mathrm{mg}, \mathrm{V}=5 \mathrm{ml}, \mathrm{pH}=5, \mathrm{~T}=25^{\circ} \mathrm{C}$ ) form aqueous solution.

\begin{tabular}{|c|c|c|c|c|c|c|c|c|}
\hline \multirow[t]{2}{*}{$M^{z+}$} & \multirow{2}{*}{$\begin{array}{l}q_{\text {exp }} \\
\mathrm{mg} \mathrm{g}^{-1}\end{array}$} & \multicolumn{3}{|c|}{ Freundlich Parameters } & \multicolumn{4}{|c|}{ Langmuir parameters } \\
\hline & & $\mathrm{K}_{\mathrm{f}}, \mathrm{mg} \mathrm{g}^{-1}$ & $\mathrm{n}$ & $\mathrm{R}^{2}$ & $\mathrm{Q}_{0}, \mathrm{mg} \mathrm{g}^{-1}$ & b, $m L \mathrm{mg}^{-1}$ & $\mathbf{R}_{\mathrm{L}}$ & $\mathbf{R}^{2}$ \\
\hline $\mathrm{Pb}^{2+}$ & 887.21 & 184.17 & 4.26 & 0.977 & 884.96 & 0.018 & 0.217 & 0.983 \\
\hline $\mathrm{Cd}^{2+}$ & 139.62 & 54.79 & 4.91 & 0.906 & 134.23 & 0.204 & 0.089 & 0.999 \\
\hline $\mathrm{Zn}^{2+}$ & 161.25 & 29.27 & 2.81 & 0.919 & 155.04 & 0.067 & 0.229 & 0.995 \\
\hline
\end{tabular}

\subsubsection{Effect of $(\mathrm{v} / \mathrm{m})$ ratio}

The effect of changing $\mathrm{v} / \mathrm{m}(\mathrm{L} / \mathrm{g})$ ratio on the sorption of $\mathrm{Pb}(\mathrm{II}), \mathrm{Cd}(\mathrm{II})$ and $\mathrm{Zn}(\mathrm{II})$ from aqueous solution on GO-SA is performed out at a v/m range of $1.79-0.357 \mathrm{~L} / \mathrm{g}$. The obtained results are given in Fig. $5 \mathrm{a}$, from which it is apparent that the sorption efficiency increases as the $\mathrm{v} / \mathrm{m}$ ratio decreases. Accordingly, for $\mathrm{Cd}$ (II) and Zn (II), the sorption percent was increased from about 67.24 to $89.45 \%$ for $(100 \mathrm{mg} / \mathrm{L}) \mathrm{Cd}$ (II) and increased from $63.72-86.90 \%$ for $(100 \mathrm{mg} / \mathrm{L}$ ) Zn (III) as $\mathrm{v} / \mathrm{m}$ decreased from 1.79 to $0.357 \mathrm{~L} / \mathrm{g}$. While for $\mathrm{Pb}$ (II), the sorption efficiency was decreased from about $57.31-87.62 \%$ for $(600 \mathrm{mg} / \mathrm{L}) \mathrm{Pb}$ (III) as $\mathrm{v} / \mathrm{m}$ decreased from 1.79 to $0.357 \mathrm{~L} / \mathrm{g}$. Therefore, the $\mathrm{v} / \mathrm{m}$ ratio $0.446 \mathrm{~L} / \mathrm{g}$ was selected for the removal process in the following experiments. This manner is attributed to, at low $\mathrm{v} / \mathrm{m}$ ratio the number of the available active sites will be sufficient to adsorb the most of adsorbate species. As the $\mathrm{v} / \mathrm{m}$ ratio 
increase the number of the metal ion in the solution increase while the number of the binding sites maintain constant. Therefore, large number of the adsorbate species residue in the aqueous solution after the adsorption process, hence, the uptake efficiency will be reduced (Abu Elgoud et al., 2019).

\subsubsection{Effect of solution Temperature}

The impact of aqueous solution temperature in rang $\left(25-65^{\circ} \mathrm{C}\right)$ on the removal percent $(\% \mathrm{R})$ of the examined heavy metal ion on the GO-SA composite was presented in Fig. $5 \mathrm{~b}$. It was noted that, the sorption efficiency of the all studied metals was increased with increase in the solution temperature from 25 to $65^{\circ} \mathrm{C}$. This is due to, the increasing in the solution temperature will enhance the movement of the metal ion species from the bulk of solution to the adsorbent surface, leading to increase the complexation chance between the metal ion and the surface function groups.

For exploring the thermodynamic parameters, (see supplementary materials) of the adsorption process of the selected metal ions on the GO-SA composite, free energy, entropy and enthalpy were calculated referring to Fig. $5 c$, the values of parameters were calculated and listed in Table 2. The negative values of $\Delta G$ indicates that the all metal studied were spontaneously sorbed on GO-SA surface. The positive values corresponding to $\Delta \mathrm{H}$ and $\Delta \mathrm{S}$ (Table 2) implies that the endothermic adsorption process as well as the affinity of the composite to adsorb the metal ion with increase in the randomness of the system.

Table 2

Thermodynamic parameters for sorption of $\mathrm{Pb}^{2+}, \mathrm{Cd}^{2+}$ and $\mathrm{Zn}^{2+}$ ions.

\begin{tabular}{|c|c|c|c|c|c|c|c|c|c|}
\hline \multirow[t]{2}{*}{$\mathrm{T}(\mathrm{K})$} & \multicolumn{3}{|c|}{$\Delta \mathrm{G}(\mathrm{kJ} / \mathrm{mole})$} & \multicolumn{3}{|c|}{$\Delta \mathrm{H}(\mathrm{kJ} / \mathrm{mole})$} & \multicolumn{3}{|c|}{$\Delta S(\mathrm{~J} / \mathrm{mole} / \mathrm{K})$} \\
\hline & $\mathrm{Pb}^{2+}$ & $\mathrm{Cd}^{2+}$ & $\mathrm{Zn}^{2+}$ & $\mathrm{Pb}^{2+}$ & $\mathrm{Cd}^{2+}$ & $\mathrm{Zn}^{2+}$ & $\mathrm{Pb}^{2+}$ & $\mathrm{Cd}^{2+}$ & $\mathrm{Zn}^{2+}$ \\
\hline 298 & -25.70 & -24.41 & -22.68 & 11.52 & 24.27 & 10.18 & 124.89 & 163.35 & 110.26 \\
\hline 308 & -26.95 & -26.04 & -23.78 & & & & & & \\
\hline 318 & -28.20 & -27.68 & -24.88 & & & & & & \\
\hline 328 & -29.44 & -29.31 & -25.99 & & & & & & \\
\hline 338 & -30.69 & -30.94 & -27.09 & & & & & & \\
\hline
\end{tabular}

\subsection{Regeneration- Reuse}

The adsorption-desorption behavior of the adsorbent material is a key index to estimate the suitability of the adsorbent employment in actual sewage management. In this regard, a definite amount of the adsorbent was utilized for adsorption of the studied metals ions. After achieving equilibrium, the supernatants were separated and the \%R were calculated. The GO-SA-M material was washed by solutions of $5.0 \mathrm{~mL}(0.5 \mathrm{M} \mathrm{HCl})$ to remove all sorbed metal ions and regenerated. The composite was treated by as $5.0 \mathrm{~mL}\left(0.5 \mathrm{M} \mathrm{NaOH}\right.$ ) and final $5 \mathrm{~mL}$ (distilled $\mathrm{H}_{2} \mathrm{O}$ ) to perform the next use. As presented in 
Fig. 5d, GO-SA showed excellent reproducibility for adsorbing of $\left(\mathrm{Pb}^{2+}, \mathrm{Cd}^{2+}, \mathrm{Zn}^{2+}\right)$ over five adsorption/desorption experimental runs. However, we observed that the removal efficiency of the regenerated composite of all studied metal ions was enhanced compared to the original composite. This is may be attributed to the regeneration solutions activated extra binding site and make them available for adsorption more metal ions.

\subsection{Selectivity behavior towards $\mathrm{Pb}^{2+}$}

Based on the adsorption experimental results, the selectivity of $\mathrm{Pb}^{2+}$ adsorption by GO-SA was assessed relative to $\mathrm{Cd}^{2+}$ and $\mathrm{Zn}^{2}$. These metal ions could be considered as competitive species during the adsorption of $\mathrm{Pb}^{2+}$ from acidic aqueous solution at $\mathrm{pH}=1$ containing $\mathrm{Cd}^{2+}$ and $\mathrm{Zn}^{2}$, as present in Fig. 5e. The affinity of the GO-SA adsorbent towards the tested metal ion in order $\mathrm{Pb}^{2+}(57.21 \%)>\mathrm{Cd}^{2+}(10.65 \%)$ $>\mathrm{Zn}^{2+}(8.21 \%)$ from initial metal ion concentration 600,100 and $100 \mathrm{mg} \mathrm{L}^{-1}$, respectively. The previous results implies that the GO-SA own an excellent ability to select removal of $\mathrm{Pb}^{2+}$ from metal ion mixture solution at $\mathrm{pH}=1$.

\subsection{Comparison with other adsorbent material}

The efficiency of sodium alginate modified graphene oxide as an adsorbent for removal of $\mathrm{Pb}^{2+}, \mathrm{Cd}^{2+}$ and $\mathrm{Zn}^{2+}$ from aqueous solution was estimated by comparing the adsorption capacity with other adsorbent materials in the literature presented in Table 3. The data showed that sodium alginate modified graphene oxide have a highly feasible capacity for the sorption of studied metal ions compared with other adsorbent materials. Therefore, sodium alginate modified graphene oxide could be used as a highly effective adsorbent for removal these metals from aqueous solutions. 
Table 3

Adsorption capacities of different adsorbents of $\mathrm{Pb}^{2+}, \mathrm{Cd}^{2+}$ and $\mathrm{Zn}^{2}$

\begin{tabular}{|c|c|c|c|}
\hline Adsorbate & Adsorbent & $\mathrm{q}_{\mathrm{o}}(\mathrm{mg} / \mathrm{g})$ & Ref. \\
\hline \multirow[t]{15}{*}{$\mathrm{Pb}^{2+}$} & (GO-Zr-P) nanocomposite & 363.42 & $\begin{array}{l}\text { (Pourbeyram, } \\
\text { 2016) }\end{array}$ \\
\hline & zinc oxide/graphene oxide nanocomposite & 418.78 & $\begin{array}{l}\text { (Ahmed et al., } \\
\text { 2020) }\end{array}$ \\
\hline & rGO-Fe0/Fe304-PEI nanocomposite & 60.24 & $\begin{array}{l}\text { (Bagheri et al., } \\
\text { 2020) }\end{array}$ \\
\hline & graphene oxide-terminated hyperbranched amino & 152.86 & (Kong et al., 2020) \\
\hline & $\begin{array}{l}\text { polymer-carboxymethyl cellulose ternary } \\
\text { nanocomposite }\end{array}$ & & \\
\hline & oily sludge pyrolysis residue & 140.65 & (Yang et al., 2020) \\
\hline & $\begin{array}{l}\text { Graphene Oxide/Sodium Alginate/1, 2- } \\
\text { Propanediamine composite membrane }\end{array}$ & 189.25 & (Yu et al., 2021) \\
\hline & Sodium alginate/graphene oxide aerogel & 267.4 & ( Jiao et al., 2016) \\
\hline & $\begin{array}{l}\text { 3D porous graphene/lignin/sodium alginate } \\
\text { composite }\end{array}$ & 226.24 & (Zhou et al., 2018) \\
\hline & $\begin{array}{l}\text { a porous calcium alginate/graphene oxide } \\
\text { composite aerogel }\end{array}$ & 368.2 & ( Pan et al., 2018) \\
\hline & EDTA-GO & 508.4 & (Cui et al., 2015) \\
\hline & Functionalized graphene (GNSPF6) & 406.4 & ( Deng et al., 2010) \\
\hline & GO & 35.6 & (Lee \& Yang, 2012) \\
\hline & $\mathrm{GO}-\mathrm{TiO}_{2}$ & 65.6 & (Lee \& Yang, 2012) \\
\hline & GO-SA & 887.21 & This work \\
\hline \multirow[t]{6}{*}{$\mathrm{Cd}^{2+}$} & rGO-Fe0/Fe304-PEl nanocomposite & 54.47 & $\begin{array}{l}\text { (Bagheri et al., } \\
2020 \text { ) }\end{array}$ \\
\hline & oily sludge pyrolysis residue & 106.16 & (Yang et al., 2020) \\
\hline & $\begin{array}{l}\text { 3D porous graphene/lignin/sodium alginate } \\
\text { composite }\end{array}$ & 79.88 & (Zhou et al., 2018) \\
\hline & Functionalized graphene (GNSPF6) & 73.42 & ( Deng et al., 2010) \\
\hline & GO & 14.9 & (Lee \& Yang, 2012) \\
\hline & $\mathrm{GO}-\mathrm{TiO}_{2}$ & 72.8 & (Lee \& Yang, 2012) \\
\hline
\end{tabular}




\begin{tabular}{|c|c|c|c|}
\hline Adsorbate & Adsorbent & $\mathrm{q}_{\mathrm{o}}(\mathrm{mg} / \mathrm{g})$ & Ref. \\
\hline & $\mathrm{RGO}-\mathrm{Fe}(0) / \mathrm{Fe} 304$ & 1.91 & $\begin{array}{l}\text { (Bhunia et al., } \\
\text { 2012) }\end{array}$ \\
\hline & GO-SA & 139.62 & This work \\
\hline \multirow[t]{7}{*}{$\mathrm{Zn}^{2+}$} & GO & 30.1 & (Lee \& Yang, 2012) \\
\hline & GO-TiO2 & 88.9 & (Lee \& Yang, 2012) \\
\hline & Mango peel & 28.2 & (lqbal et al., 2009) \\
\hline & magnetite (MG) & 33.95 & $\begin{array}{l}\text { (Abdus Salam } \\
\text { and Adekola,2018) }\end{array}$ \\
\hline & baobab fruit shell (BB) & 29.20 & $\begin{array}{l}\text { (Abdus Salam } \\
\text { and Adekola,2018 }\end{array}$ \\
\hline & magnetite-baobab composite (MB) & 38.25 & $\begin{array}{l}\text { (Abdus Salam } \\
\text { and Adekola,2018 }\end{array}$ \\
\hline & GO-SA & 161.25 & This work \\
\hline
\end{tabular}

\section{Conclusion}

In this paper we succeed to modify the GO with highly active biopolymer (SA) through mild condition. The as-synthesised composite (GO-SA) was characterized by TEM, SEM, FTIR, Raman, TGA and EDX. The activity of the GO-SA was evaluated using batch adsorption process of different heavy metal. According to Langmuir isotherm model the GO-SA achieve maximum adsorption capacity $887.21,161.25$ and $139.62 \mathrm{mg} \mathrm{g}^{-1}$ for $\mathrm{Pb}^{2+}, \mathrm{Zn}^{2+}$ and $\mathrm{Cd}^{2+}$, respectively. Moreover, the GO-SA represent excellent regeneration ability with enhancing the removal efficiency over five reuse runs. In addition, the GO-SA composite can selective adsorb $\mathrm{Pb}$ (II) from low acid of $\mathrm{pH}=1$ in presence of $\mathrm{Cd}(\mathrm{II})$ and $\mathrm{Zn}$ (II).

\section{References}

1. Abd-Elhamid, A. I., Aly, H. F., Soliman, H. A., \& El-Shanshory, A. A. (2018). Graphene oxide: Follow the oxidation mechanism and its application in water treatment. Journal of Molecular Liquids, 265, 226237. https://doi.org/10.1016/j.molliq.2018.05.127

2. Abdus-Salam, N., \& Adekola, S. K. (2018). Adsorption studies of zinc (II) on magnetite, baobab (Adansonia digitata) and magnetite-baobab composite. Applied Water Science, 8(8), 1-11.

3. Ablouh, E. H., Hanani, Z., Eladlani, N., Rhazi, M., \& Taourirte, M. (2019). Chitosan microspheres/sodium alginate hybrid beads: an efficient green adsorbent for heavy metals removal from aqueous solutions. Sustainable Environment Research, 29(1), 1-11.

https://doi.org/10.1186/s42834-019-0004-9 
4. Abu Elgoud EM, Ismail ZH, El-Nadi YA, Abdelwahab SM, Aly HF (2019) Extraction of some rare earth elements (La, Pr and Er) from citrate medium using D2EHPA in kerosene. Arab J Nucl Sci Appl 52:74-85

5. Aglan, R. F., \& Hamed, M. M. (2014). Optimization of environmental friendly process for removal of cadmium from wastewater. Russian Journal of Applied Chemistry, 87(3), 373-382. https://doi.org/10.1134/S1070427214030215

6. Ahmad, S. Z. N., Salleh, W. N. W., Yusof, N., Yusop, M. Z. M., Hamdan, R., Awang, N. A., Ismail, N.H., Rosman, N., Ibrahim, H., \& Ismail, A. F. (2020). Efficient Removal of Pb (II) from Aqueous Solution using Zinc Oxide/Graphene Oxide Composite. In IOPConference Series: Materials Science and Engineering 736, 052002 .IOP Publishing. https://doi.org/10.1088/1757-899X/736/5/052002

7. Ali, S. A., \& Ache, H. J. (1985). Separation and purification of fission products from process streams of irradiated nuclear fuel. Radiochim. Acta 40 (1986) 1.

8. Allouss, D., Essamlali, Y., Chakir, A., Khadhar, S., \& Zahouily, M. (2020). Effective removal of Cu (II) from aqueous solution over graphene oxide encapsulated carboxymethylcellulose-alginate hydrogel microspheres: towards real wastewater treatment plants. Environmental Science and Pollution Research, 27(7), 7476-7492.

9. Bagheri, S., Esrafili, A., Kermani, M., Mehralipour, J., \& Gholami, M. (2020). Performance evaluation of a novel rGO-Fe0/Fe304-PEI nanocomposite for lead and cadmium removal from aqueous solutions. Journal of Molecular Liquids, 320, 114422.

10. Bhunia, P., Kim, G., Baik, C., \& Lee, H. (2012). A strategically designed porous iron-iron oxide matrix on graphene for heavy metal adsorption. Chemical communications, 48(79), 9888-9890.

11. Carolin, C. F., Kumar, P. S., Saravanan, A., Joshiba, G. J., \& Naushad, M. (2017). Efficient control. Proceedings of the 11th international congress of the International Radiation Protection Association, France.

12. Cui, L., Wang, Y., Gao, L., Hu, L., Yan, L., Wei, Q., \& Du, B. (2015). EDTA functionalized magnetic graphene oxide for removal of $\mathrm{Pb}$ (II), $\mathrm{Hg}$ (II) and $\mathrm{Cu}$ (II) in water treatment: adsorption mechanism and separation property. Chemical engineering journal, 281, 1-10.

13. Dodd, B. (2020). Safety and Security of Radioactive Sources: Conflicts, Commonalities and Control". Current trends in radiation protection, Les Ulis: EDP Sciences, 165-

176. https://doi.org/10.1051/978-2-7598-0117-6.c016

14. Febrianastuti, S., Fadillah, G., Putri, E. N. K., Apriani, U. W., \& Wahyuningsih, S. (2019). Effect of pH $\mathrm{CaCl}_{2}$ solution on graphene oxide encapsulated alginate (GO-AL) for removing methylene blue dyes. In IOP Conference Series: Materials Science and Engineering 509 (2019) 012143. doi:10.1088/1757$899 X / 509 / 1 / 012143$

15. Ge, H., \& Ma, Z. (2015). Microwave preparation of triethylenetetramine modified graphene oxide/chitosan composite for adsorption of $\mathrm{Cr}(\mathrm{VI})$. Carbohydrate polymers, 131, 280-287.

16. Deng, X., Lu, L., Li, H., Luo, F., 2010. The adsorption properties of $\mathrm{Pb}(\mathrm{II})$ and $\mathrm{Cd}(\mathrm{II})$ on functionalized graphene prepared by electrolysis method. J. Hazard. Mater. 183,923-930. 
17. Gopalakannan, V., \& Viswanathan, N. (2016). One pot synthesis of metal ion anchored alginategelatin binary biocomposite for efficient $\mathrm{Cr}(\mathrm{Vl})$ removal. International journal of biological macromolecules, 83, 450-459.

18. Guo, T., Bulin, C., Li, B., Zhao, Z., Yu, H., Sun, H., Ge, X., Xing, R., \& Zhang, B. (2018). Efficient removal of aqueous $\mathrm{Pb}$ (II) using partially reduced graphene oxide- $\mathrm{Fe}_{3} \mathrm{O}_{4}$.Adsorption Science \& Technology, 36(3-4), 1031- 1048.https://doi.org/10.1177/0263617417744402

19. He, J., Ni, F., Cui, A., Chen, X., Deng, S., Shen, F., \& Luo, L. (2020). New insight into adsorption and coadsorption of arsenic and tetracycline using a $\mathrm{Y}$-immobilized graphene oxide-alginate hydrogel: Adsorption behaviours and mechanisms. Science of The Total Environment, 701, 134363.

20. Huang, Y., \& Wang, Z. (2018). Preparation of composite aerogels based on sodium alginate, and its application in removal of $\mathrm{Pb}^{2+}$ and $\mathrm{Cu}^{2+}$ from water. International journal of biological macromolecules, 107, 741-747.

21. Jiao, C., Xiong, J., Tao, J., Xu, S., Zhang, D., Lin, H., \& Chen, Y. (2016). Sodium alginate/graphene oxide aerogel with enhanced strength-toughness and its heavy metal adsorption study. International journal of biological macromolecules, 83, 133-141. https://doi.org/10.1016/j.ijbiomac.2015.11.061

22. Katubi, K. M. M., Alsaiari, N. S., Alzahrani, F. M., M Siddeeg, S., \& A Tahoon, M. (2021) Synthesis of manganese ferrite/graphene oxide magnetic nanocomposite for pollutants removal from water. Processes, 9(4), 589. https://doi.org/10.3390/pr9040589

23. Kong, Q., Preis, S., Li, L., Luo, P., Hu, Y., \&Wei, C.(2020) Graphene oxide-.for efficient removal of heavy metals from aqueous solutions, International Journal of Biological Macromolecules 149 (2020) 581-592https://doi.org/10.1016/j.jibiomac.2020.01.185

24. Li, L., Zhao, L., Ma, J., \& Tian, Y. (2020). Preparation of graphene oxide/chitosan complex and its adsorption properties for heavy metal ions. Green Processing and Synthesis, 9(1), 294-303. https://doi.org/10.1515/gps-2020-0030

25. Liu, X., Li, J., Wang, X., Chen, C., \& Wang, X. (2015). High performance of phosphate- functionalized graphene oxide for the selective adsorption of $\mathrm{U}(\mathrm{VI})$ from acidic solution. Journal of Nuclear Materials, 466, 56-64. https://doi.org/10.1016/j.jnucmat.2015.07.027

26. Liu, Y., Zhao, J. C., Zhang, C. J., Guo, Y., Cui, L., Zhu, P., \& Wang, D. Y. (2015). Bio- based nickel alginate and copper alginate films with excellent flame retardancy: preparation, flammability and thermal degradation behavior. RSC advances, 5(79), 64125-64137.

27. Lee, Y. C., \& Yang, J. W. (2012). Self-assembled flower-like $\mathrm{TiO}_{2}$ on exfoliated graphite oxide for heavy metal removal. Journal of industrial and engineering chemistry, 18(3), 1178-1185.

28. Marczenko, Z. (1976). Spectrophotometric Determination of Elements; Ellis Harwood Ltd: Poland.

29. Nigiz, F. U. (2020). Graphene oxide-sodium alginate membrane for seawater desalination through pervaporation. Desalination, 485, 114465. https://doi.org/10.1016/j.desal.2020.114465

30. Nurhajawarsi, N., Rafi, M., Syafitri, U. D., \& Rohaeti, E. (2018). L-Histidine-Modified Silica from Rice Husk and Optimization of Adsorption Condition for Extractive Concentration of Pb (II). The Journal 
of Pure and Applied Chemistry Research, 7(2), 198

31. Pan, L., Wang, Z., Yang, Q., \& Huang, R. (2018). Efficient removal of lead, copper and cadmium ions from water by a porous calcium alginate/graphene oxide composite aerogel. Nanomaterials, $8(11)$, 957. doi:10.3390/nano8110957

32. Pourbeyram, S. (2016). Effective removal of heavy metals from aqueous solutions by graphene oxide-zirconium phosphate (GO-Zr-P) nanocomposite. Industrial \& Engineering Chemistry Research, 55(19), 5608-5617. https://doi.org/10.1021/acs.iecr.6b00728

33. Rodríguez, C., Tapia, C., Leiva-Aravena, E., \& Leiva, E. (2020). Graphene oxide-ZnO nanocomposites for removal of aluminum and copper ions from acid mine drainage wastewater. International Journal of Environmental Research and PublicHealth, 17(18), 6911. https://doi.org/10.3390/ijerph17186911

34. Taamneh, Y., \& Sharadqah, S. (2017). The removal of heavy metals from aqueous solution using natural Jordanian zeolite. Applied Water Science, 7(4), 2021-2028.

35. techniques for the removal of toxic heavy metals from aquatic environment: A review. Journal of environmental chemical engineering, 5(3), 2782-2799. https://doi.org/10.1016/j.jece.2017.05.029.

36. Wang, Z., Huang, Y., Wang, M., Wu, G., Geng, T., Zhao, Y., \& Wu, A. (2016). Macroporous calcium alginate aerogel as sorbent for $\mathrm{Pb}^{2+}$ removal from water media. Journal of environmental chemical engineering, 4(3), 3185-3192.

37. Yang, H., Li, Z., Ma, W., \& Fu, P. (2020). Evaluation of pyrolysis residue derived by oily sludge on removing heavy metals from artificial flotation wastewater. South AfricanJournal of Chemical Engineering, 34, 82-89. https://doi.org/10.1016/j.sajce.2020.06.005

38. Yang, Y., Wu, W. Q., Zhou, H. H., Huang, Z. Y., Ye, T. T., Liu, R., \& Kuang, Y. F. (2014). Adsorption behavior of cross-linked chitosan modified by graphene oxide for $\mathrm{Cu}$ (II) removal. Journal of Central South University, 21(7), 2826-2831.

39. Yu, Y., Sun, R., Wang, Z., Yao, M., \& Wang, G. (2021). Self-supported Graphene Oxide/Sodium Alginate/1, 2-Propanediamine composite membrane and its $\mathrm{Pb}^{2+}$ adsorption capability. Journal of Environmental Chemical Engineering, 9(5), 106254.

40. Yu, Y., Zhang, G., \& Ye, L. (2019). Preparation and adsorption mechanism of polyvinyl alcohol/graphene oxide-sodium alginate nanocomposite hydrogel with high $\mathrm{Pb}$ (II) adsorption capacity. Journal of Applied Polymer Science, 136(14), 47318.

41. Zhang, W., An, Y., Li, S., Liu, Z., Chen, Z., Ren, Y., Wang, S., Zhang, X., \& Wang, X. (2020). Enhanced heavy metal removal from an aqueous environment using an eco-friendly and sustainable adsorbent. Scientific reports, 10(1), 1-19. | https://doi.org/10.1038/s41598-020- 735707

42. Zhou, F., Feng, X., Yu, J., \& Jiang, X. (2018). High performance of 3D porous graphene/lignin/sodium alginate composite for adsorption of $\mathrm{Cd}$ (II) and $\mathrm{Pb}$ (II). Environmental Science and Pollution Research, 25(16), 15651-15661. https://doi.org/10.1007/s11356-018-1733-8

\section{Figures}



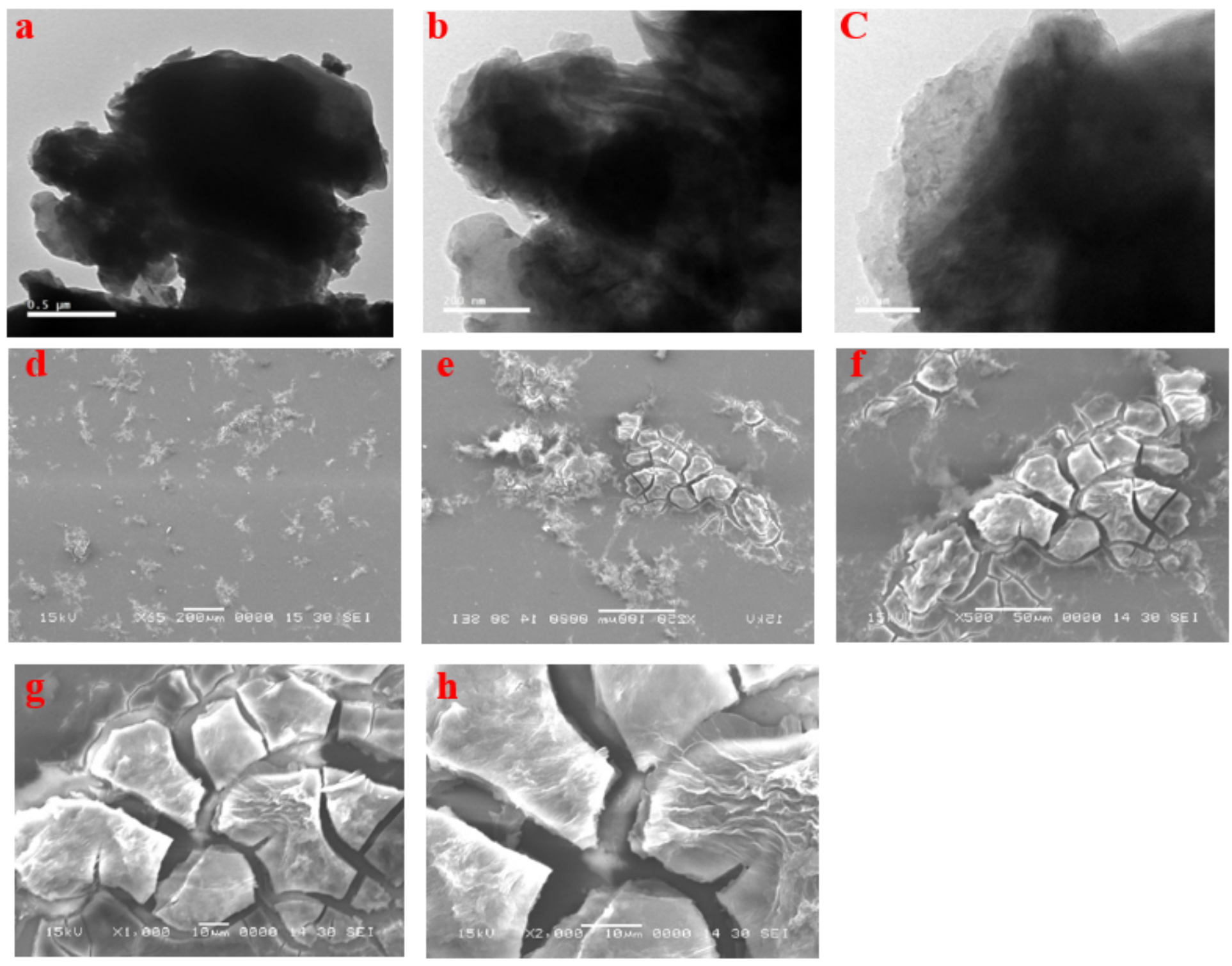

\section{Figure 1}

TEM (a-c) and SEM (d-h) images for alginate modified graphene oxide (GO-SA). 

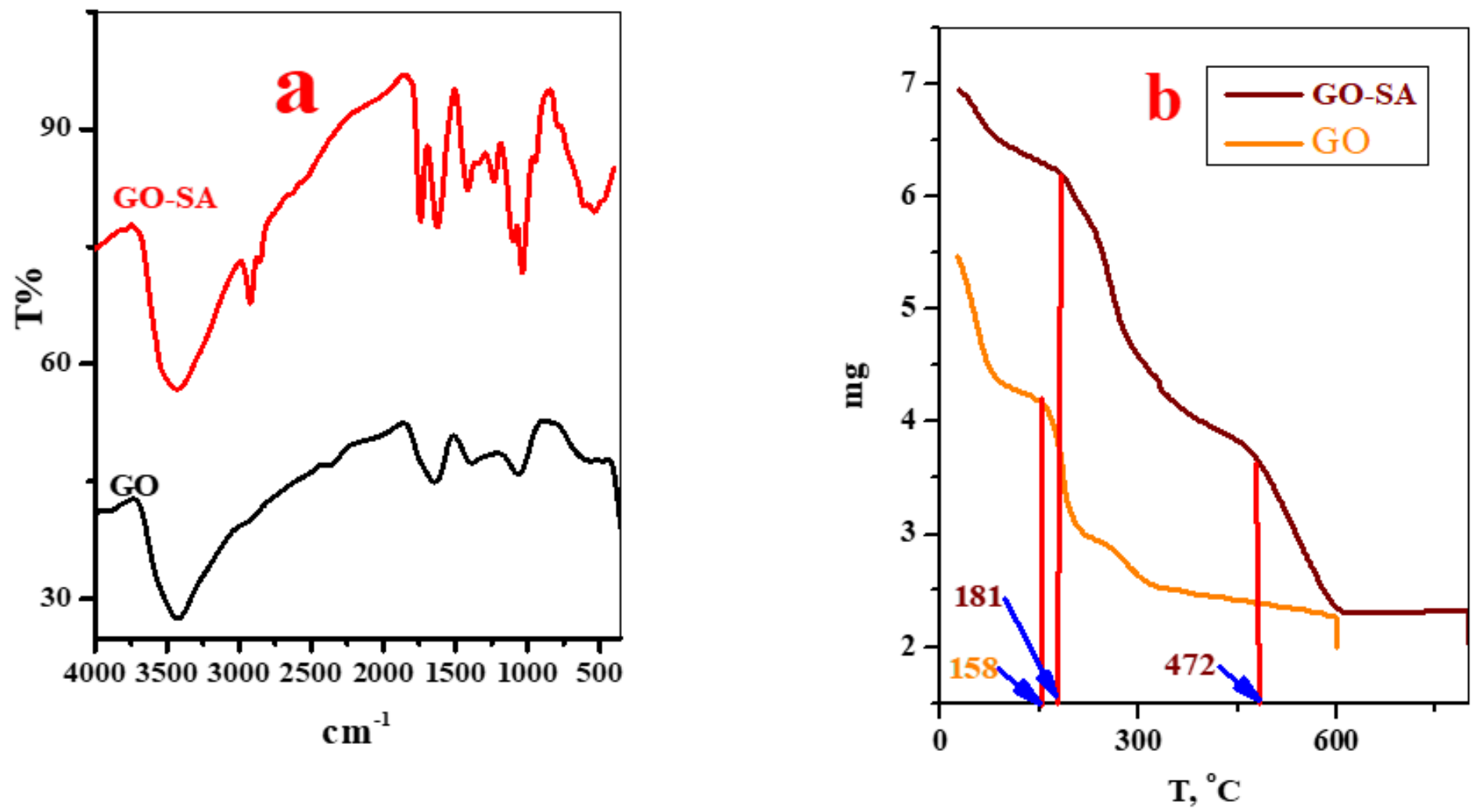

Figure 2

a) FT-IR spectrum of GO and GO-SA composite and b) Thermogravimetric diagram of GO and GO-SA composite. 


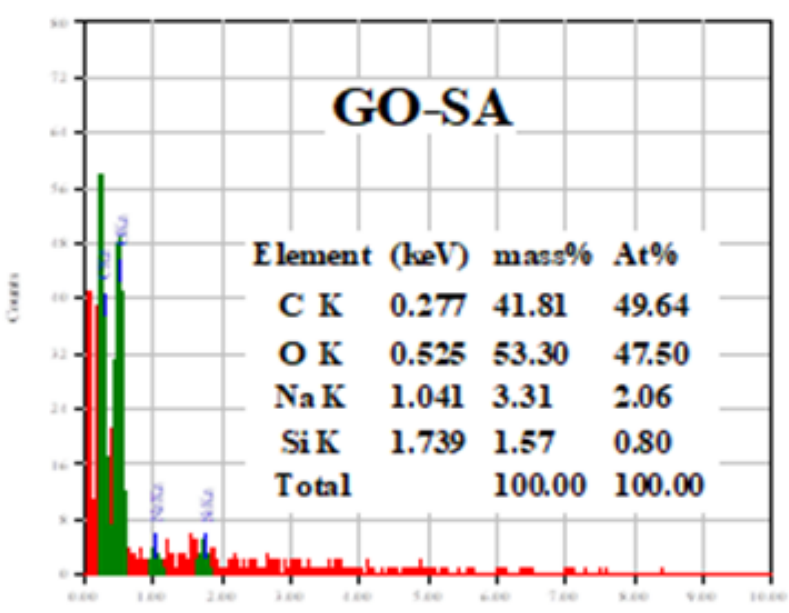

tit

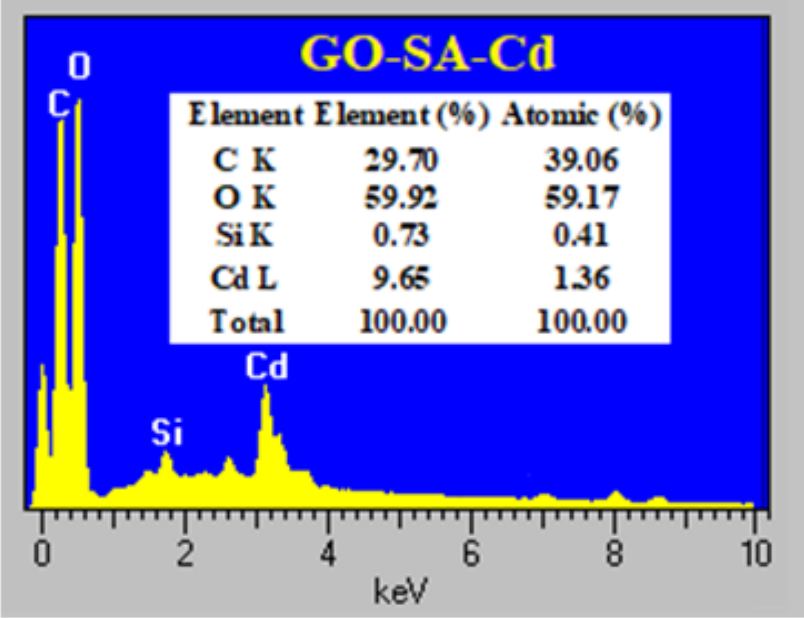

\section{GO-SA-Pb}
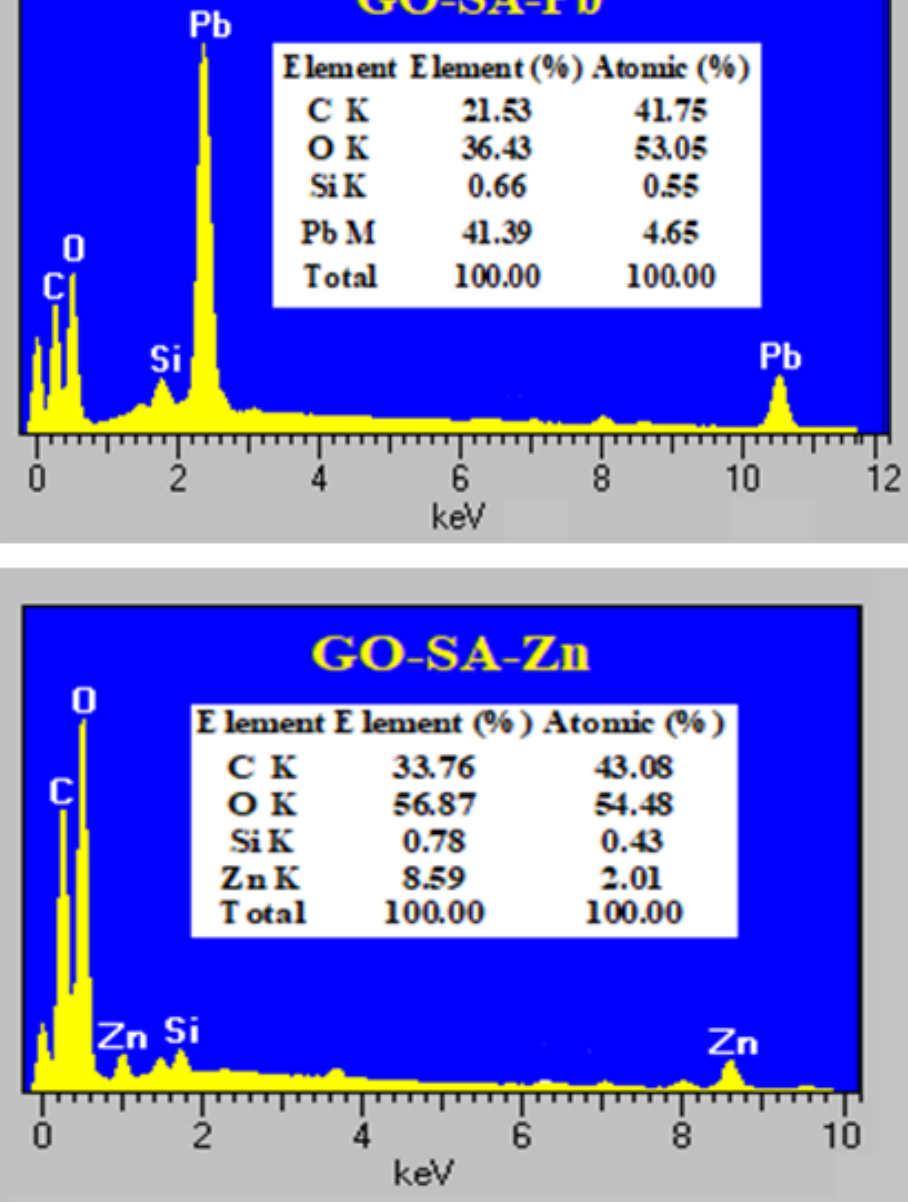

Figure 3

EDS and EDX analysis for GO-SA composite, GO-SA-Pb complex, GO-SA-Cd complex and GO-SA-Zn complex 

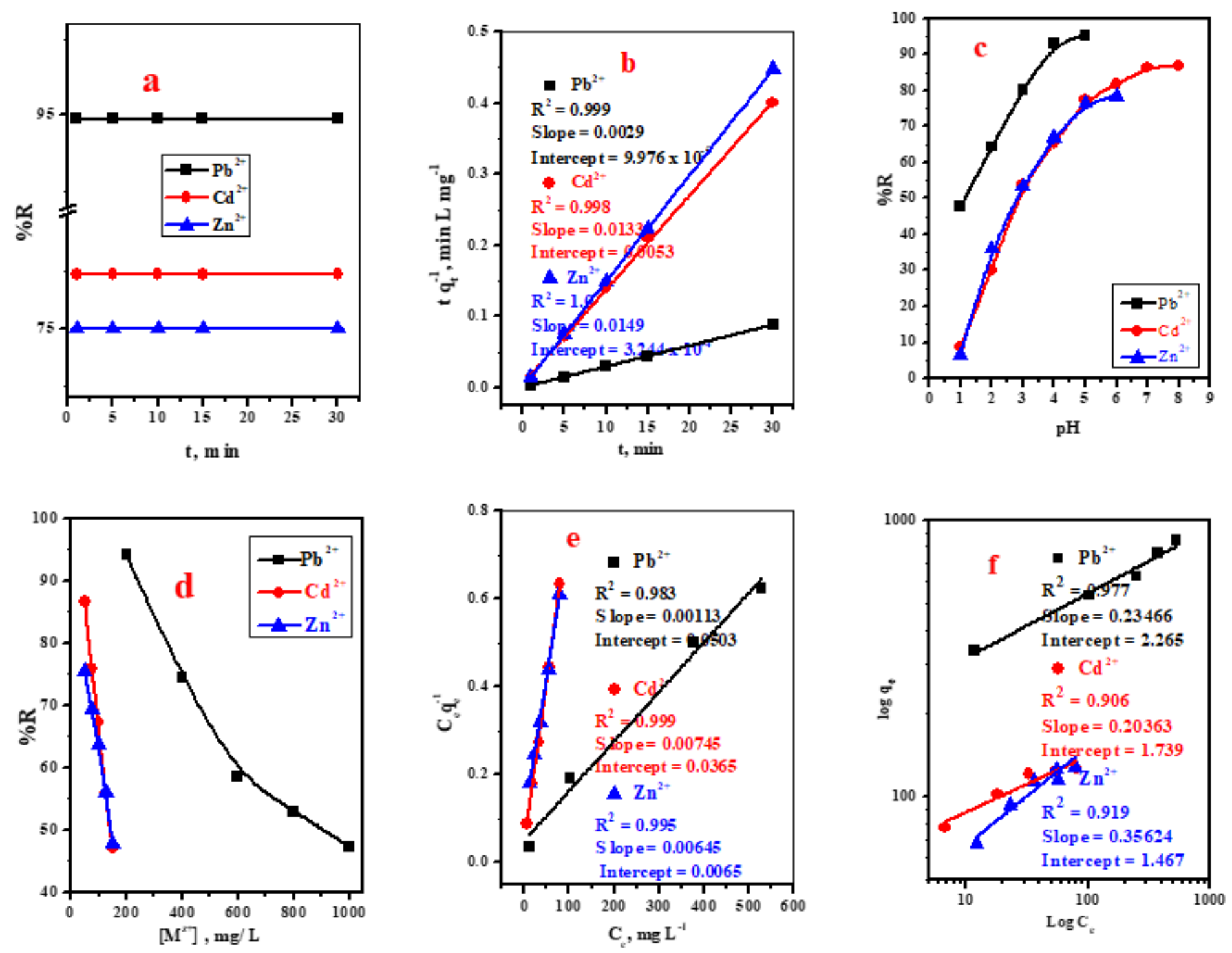

Figure 4

Effect of a) contact time on removal percent $(\% \mathrm{R}), \mathrm{b}) 2^{\text {nd }}$ order kinetic model of $\mathrm{Pb}^{2+}\left(\left[\mathrm{Pb}^{2+}\right]=200 \mathrm{mg} \mathrm{L}^{-1}\right.$, Dose $\left.=2.8 \mathrm{mg}, \mathrm{v}=5 \mathrm{ml}, \mathrm{pH}=5, \mathrm{~T}=25^{\circ} \mathrm{C}\right) \mathrm{Cd}^{2+}\left(\left[\mathrm{Cd}^{2+}\right]=50 \mathrm{mg} \mathrm{L}^{-1}\right.$, Dose $=2.8 \mathrm{mg}, \mathrm{v}=5 \mathrm{ml}, \mathrm{pH}=5, \mathrm{~T}=25$ $\left.{ }^{\circ} \mathrm{C}\right)$ and $\mathrm{Zn}^{2+}\left(\left[\mathrm{Zn}^{2+}\right]=50 \mathrm{mg} \mathrm{L}^{-1}\right.$, Dose $\left.=2.8 \mathrm{mg}, \mathrm{v}=5 \mathrm{ml}, \mathrm{pH}=5, \mathrm{~T}=25^{\circ} \mathrm{C}\right)$ from aqueous media. $\left.\mathrm{C}\right)$ Effect of the initial solution $\mathrm{pH}$ on the removal percentage $(\% \mathrm{R})$ from aqueous solution of $\mathrm{Pb}^{2+}(\mathrm{t}=1.0$ $\min ,\left[\mathrm{Pb}^{2+}\right]=200 \mathrm{mg} \mathrm{L}^{-1}$, Dose $\left.=2.8 \mathrm{mg}, \mathrm{V}=5 \mathrm{ml}, \mathrm{T}=25^{\circ} \mathrm{C}\right) \mathrm{Cd}^{2+}\left(\mathrm{t}=1.0 \mathrm{~min}\left[\mathrm{Cu}^{2+}\right]=50 \mathrm{mg} \mathrm{L}^{-1}\right.$, Dose $=$ $\left.2.8 \mathrm{mg}, \mathrm{V}=5 \mathrm{ml}, \mathrm{T}=25^{\circ} \mathrm{C}\right)$ and $\mathrm{Zn}^{2+}\left(\mathrm{t}=1 \mathrm{~min},\left[\mathrm{Zn}^{2+}\right]=50 \mathrm{mg} \mathrm{L}^{-1}\right.$, Dose $\left.=2.8 \mathrm{mg}, \mathrm{V}=5 \mathrm{ml}, \mathrm{T}=25^{\circ} \mathrm{C}\right)$ form aqueous media.

d) metal ion concentration on removal percent, e) Langmuir isotherm plot, f) Freundlich isotherm plot of $\mathrm{Pb}^{2+}\left(\mathrm{t}=1 \mathrm{~min}\right.$, Dose $\left.=2.8 \mathrm{mg}, \mathrm{v}=5 \mathrm{ml}, \mathrm{pH}=4, \mathrm{~T}=25^{\circ} \mathrm{C}\right) \mathrm{Cd}^{2+}(\mathrm{t}=1 \mathrm{~min}$, Dose $=2.8 \mathrm{mg}, \mathrm{v}=5 \mathrm{ml}, \mathrm{pH}=7, \mathrm{~T}$ $\left.=25^{\circ} \mathrm{C}\right)$ and $\mathrm{Zn}^{2+}\left(\mathrm{t}=1 \mathrm{~min}\right.$, Dose $\left.=2.8 \mathrm{mg}, \mathrm{v}=5 \mathrm{ml}, \mathrm{pH}=5, \mathrm{~T}=25^{\circ} \mathrm{C}\right)$ form aqueous solution. 

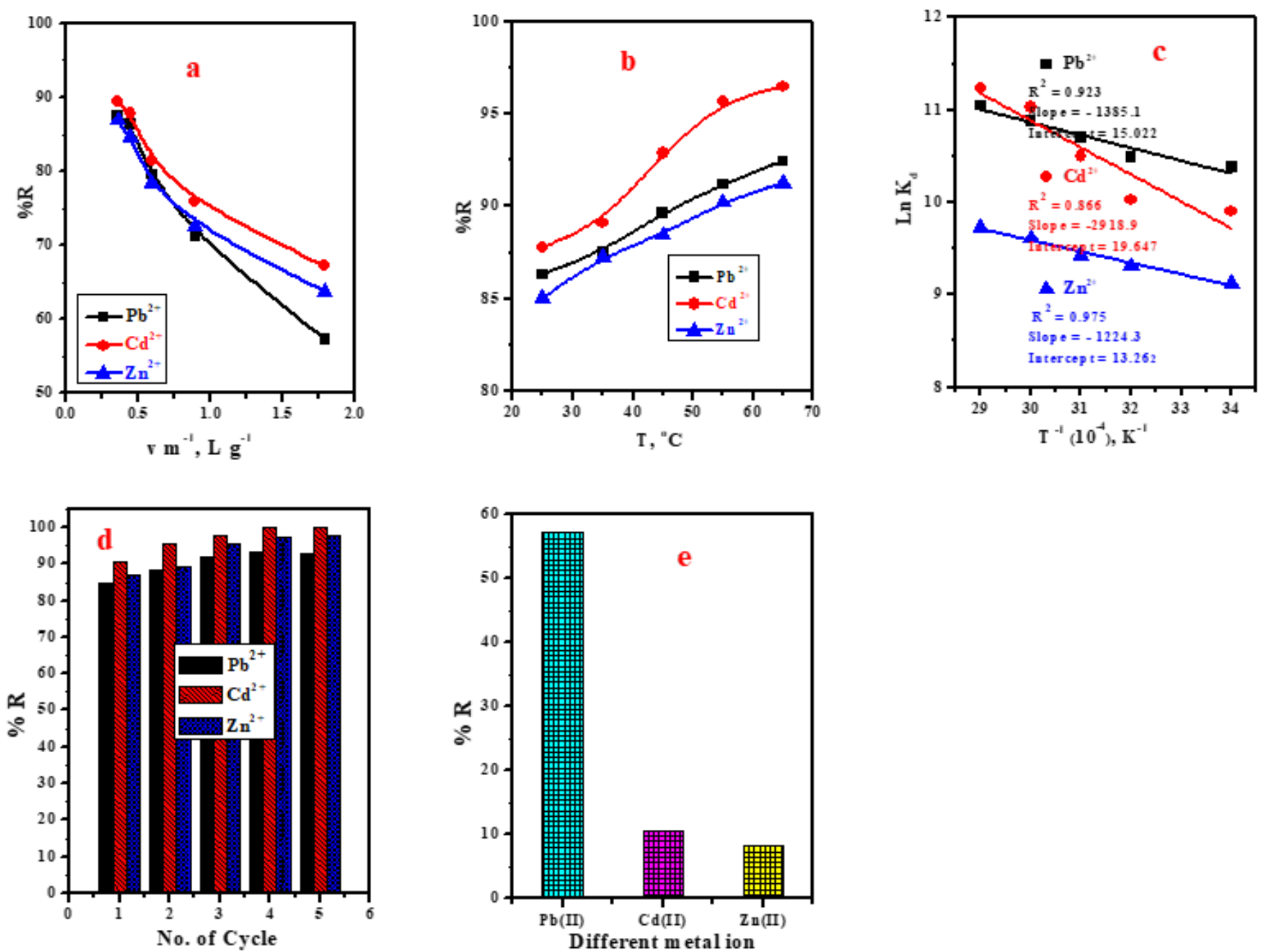

Different $m$ etal ion

\section{Figure 5}

Effect of a) $\mathrm{v} / \mathrm{m}$ ratio on sorption of $\mathrm{Pb}^{2+}\left(\mathrm{t}=1 \mathrm{~min},[\mathrm{~Pb}]=600 \mathrm{mg} \mathrm{L}^{-1}, \mathrm{v}=5 \mathrm{ml}, \mathrm{pH}=4, \mathrm{~T}=25^{\circ} \mathrm{C}\right), \mathrm{Cd}^{2+}(\mathrm{t}=$ $\left.1 \mathrm{~min},[\mathrm{Cd}]=100 \mathrm{mg} \mathrm{L}^{-1}, \mathrm{v}=5 \mathrm{ml}, \mathrm{pH}=7, \mathrm{~T}=25^{\circ} \mathrm{C}\right)$ and $\mathrm{Co}^{2+}\left(\mathrm{t}=1 \mathrm{~min},[\mathrm{Zn}]=100 \mathrm{mg} \mathrm{L}^{-1}, \mathrm{v}=5 \mathrm{ml}, \mathrm{pH}=5, \mathrm{~T}\right.$ $=25^{\circ} \mathrm{C}$ ) form aqueous media.

b) temperature on the removal percent and $c)$ thermodynamic parameters of $\mathrm{Pb}^{2+}(\mathrm{t}=1 \mathrm{~min},[\mathrm{~Pb}]=600$ $\mathrm{mg} \mathrm{L}^{-1}$, Dose $\left.=11.2 \mathrm{mg}, \mathrm{v}=5 \mathrm{ml}, \mathrm{pH}=4, \mathrm{~T}=25^{\circ} \mathrm{C}\right) \mathrm{Cd}^{2+}\left(\mathrm{t}=1 \mathrm{~min},[\mathrm{Cd}]=100 \mathrm{mg} \mathrm{L}^{-1}\right.$, Dose $=11.2 \mathrm{mg}, \mathrm{v}=5$ $\left.\mathrm{ml}, \mathrm{pH}=7, \mathrm{~T}=25^{\circ} \mathrm{C}\right)$ and $\mathrm{Zn}^{2+}\left(\mathrm{t}=1 \mathrm{~min},[\mathrm{Zn}]=100 \mathrm{mg} \mathrm{L}^{-1}\right.$, Dose $\left.=11.2 \mathrm{mg}, \mathrm{v}=5 \mathrm{ml}, \mathrm{pH}=5, \mathrm{~T}=25^{\circ} \mathrm{C}\right)$ form aqueous solution.

d) the number of the re-use cycles of the GO-C on the removal percentage of $\mathrm{Pb}^{2+}(\mathrm{t}=1.0 \mathrm{~min},[\mathrm{~Pb}]=600$ $\mathrm{mg} / \mathrm{L}$, Dose $\left.=14 \mathrm{mg}, \mathrm{V}=5.0 \mathrm{ml}, \mathrm{pH}=4, \mathrm{~T}=25^{\circ} \mathrm{C}\right), \mathrm{Cd}^{2+}([\mathrm{Cd}]=100 \mathrm{mg} / \mathrm{L}$, Dose $=14 \mathrm{mg}, \mathrm{V}=5.0 \mathrm{ml}, \mathrm{pH}=7$, $\left.\mathrm{T}=25^{\circ} \mathrm{C}\right)$ and $\mathrm{Zn}^{2+}\left([\mathrm{Zn}]=100 \mathrm{mg} / \mathrm{L}\right.$, Dose $\left.=14 \mathrm{mg}, \mathrm{V}=5.0 \mathrm{ml}, \mathrm{pH}=5, \mathrm{~T}=25^{\circ} \mathrm{C}\right)$ from aqueous media. 
e) Selective removal of $\mathrm{Pb}$ (II) from metal ion mixture from aqueous solution. [Mz+] ([Pb] $=600.0 \mathrm{mg} / \mathrm{L}$, $[\mathrm{Cd}]=100.0 \mathrm{mg} / \mathrm{L},[\mathrm{Zn}]=100.0 \mathrm{mg} / \mathrm{L}, \mathrm{v}=10.0 \mathrm{ml}, \mathrm{m}=0.014 \mathrm{gm}, \mathrm{pH}=1.0, \mathrm{t}=1.0 \mathrm{~min}, \mathrm{~T}=25^{\circ} \mathrm{C}$

\section{Supplementary Files}

This is a list of supplementary files associated with this preprint. Click to download.

- SupplementaryMaterial.docx 